\title{
Dynamic Response of Different Types of Angle Steel Components under Explosion Loading
}

\author{
Baichun Zhong, Chuntao Zhang* and Ruheng Wang \\ School of Civil Engineering and Architecture, Southwest University of Science and Technology, Mianyang 621010, China
}

\begin{abstract}
The failure mode and antiknock performance of equilateral angle steel component were investigated by explosion experiments on 9 equilateral Angle steel specimens. The blast pressure time curve, acceleration time curve and strain time curve of each part were obtained. The deformation characteristics of equilateral Angle steel under blast load and the influence of equilateral Angle steel components on the propagation form of blast wave were studied. Because of the special structural forms of equilateral angle steel components, the blast wave was repeatedly superimposed of the explosion. The pressure peak, acceleration, strain and residual deformation of each measuring point increased with the increase of the flange width of the specimen. The pressure peak were decreasing from the point of initiation to the end of components in the near field explosion, and the pressure varied greatly at each height of the component. When the explosive dose was small, the deformation of the middle part of the blasting face was mainly local buckling, and when the explosive dose increased gradually, the overall bending phenomenon became gradually obvious.
\end{abstract}

Keywords-explosion; equilateral angle steel; dynamic response; deformation

\section{INTRODUCTION}

With the development of China's steel structure, more and more steel structures were used in large public buildings, such as: high-rise buildings, industrial buildings, transmission line towers and other structural systems. In recent years, with frequent explosion events, the anti explosion performance of structure has gradually become an important factor in structural design[1]. However, the mechanical properties and failure modes of structures under blast loading were quite different from those under static and quasi static loads[2-4].

Perzyna [5] pointed out that the construction of low carbon steel and low alloy steel under the explosive load, with the increase of strain rate, the yield strength of steel is obviously improved. The ultimate strength of the steel increased with increasing strain rate. Johnson and Cook[6] proposed the Johnson-Cook constitutive model, considering strain hardening, strain rate hardening and temperature softening, to simulate the deformation of most metals under impact loading. Dynamic response test of Nurick[7] square plates under pulse load, get three kinds of failure form of square plates: the tearing damage caused by bending deformation, tension and transverse shear failure. Nonaka[8] analyses the steel beams damaged by terrorist explosion, and points out that the main failure of steel beams and supports is shear failure under blast loading.
Li Zhongxian [9-10] pointed out that the main reason for the overall collapse of the steel frame under explosive loading is that the steel column can not restore the plastic deformation and lose its bearing capacity. As the main bearing component of transmission tower structure, the equal angle steel member will lose the local bearing capacity of the transmission tower when it is subjected to explosive impact load. A series of chain reactions and causing the destruction or collapse of the entire transmission tower structure, which will cause serious economic losses and potential casualties.

The use of equilateral steel members in transmission tower lines in China makes the study of their performance under explosive impact loading imminent and of practical significance. Based on this, the near field explosion test of 9 equilateral steel members is carried out in this paper. The influence of angle steel model and equivalent explosive on the anti explosion performance of diagonal steel members is studied.

\section{GENERAL SitUATION OF TEST}

Considering the influence of the difference of flange width and dose on the dynamic response of equal angle steel under explosion, 9 groups of working conditions were designed, Shown in Table 1 . The angle steel component is connected with the counter-force frame through the support, and the experimental device is shown in Figure 1.

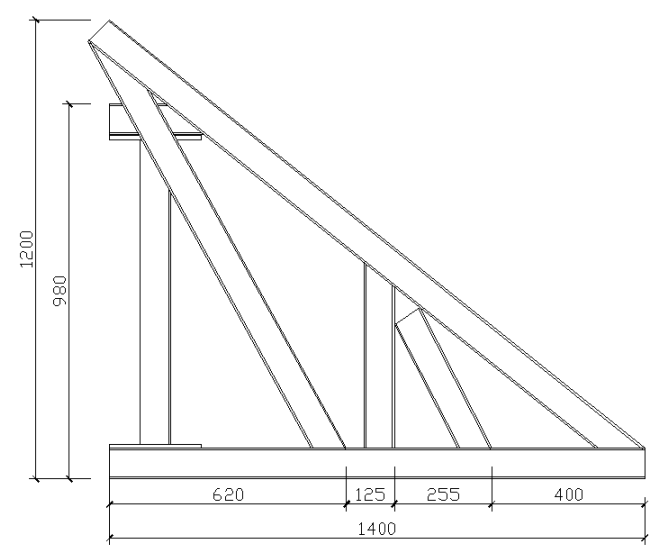

FIGURE I. DIAGRAM OF EXPERIMENTAL DEVICE 


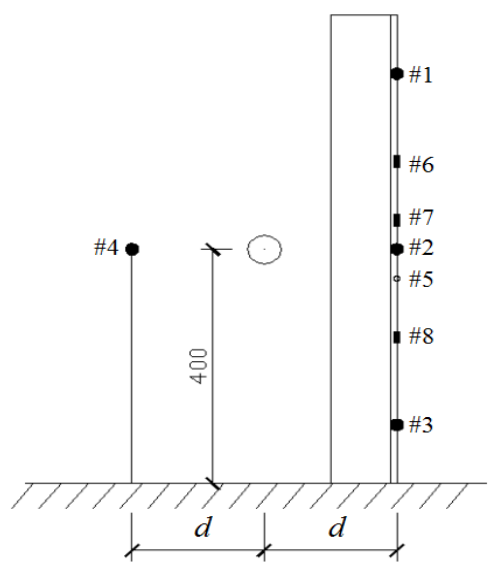

FIGURE II. ARRANGEMENT OF MEASURE POINT

TABLE I. TEST CONDITIONS

\begin{tabular}{|c|c|c|c|c|}
\hline Number & $\begin{array}{c}\text { Flange } \\
\text { width(mm) }\end{array}$ & $\begin{array}{c}\text { Flange } \\
\text { thickness } \\
\mathbf{( m m )}\end{array}$ & Dose (kg) & $\begin{array}{c}\text { Explosion } \\
\text { distance(m) }\end{array}$ \\
\hline B1-1 & 90 & 6 & 0.3 & 0.2 \\
\hline B2-1 & 100 & 6 & 0.3 & 0.2 \\
\hline B3-1 & 125 & 8 & 0.3 & 0.2 \\
\hline B1-2 & 90 & 6 & 0.5 & 0.2 \\
\hline B2-2 & 100 & 6 & 0.5 & 0.2 \\
\hline B3-2 & 125 & 8 & 0.5 & 0.2 \\
\hline B1-3 & 90 & 6 & 0.7 & 0.2 \\
\hline B2-3 & 100 & 6 & 0.7 & 0.2 \\
\hline B3-3 & 125 & 8 & 0.7 & 0.2 \\
\hline
\end{tabular}

The pressure sensors(No.1-3) were installed at the top, middle and bottom of the detonation surface of each specimen used to study the pressure distribution of detonation surface of component. The measuring point 4 is used to collect the pressure value of the shock wave propagating to the point, and the influence of the equal angle steel member on the wave propagation of the explosion shock wave was compared. The 5 measuring point is set in the middle of the specimen, and the acceleration data of the specimen under shock wave were collected. The strain measuring points 6,7 and 8 were shown in Figure 2, and the strain variation of specimen under shock wave is collected. In order to ensure the safety and accuracy of the instrument, the strain data is collected only when the explosive volume is $700 \mathrm{~g}$, and the pressure sensor 4 is moved away from the explosive $1.2 \mathrm{~m}$, and the shock wave pressure value of the point is collected.

\section{TEST RESUlTS AND ANALYSIS}

\section{A. Results of Explosion Shock Wave}

Figure3-5 showed the pressure time history curve of B1-1, B2-1 and B3-1. Due to the propagation distance is short, in the near-field explosion, the pressure rise time is very short.
Moreover, the shape of the pressure curve is disturbed greatly, and there were many peaks in the pressure of each specimen, and the oscillation is violent. It can be clearly seen that the pressure of explosion shock wave passes through the stage of positive pressure and negative pressure, and the peak value of negative pressure is smaller than that of positive pressure. The influence of negative pressure on the specimen was not obvious. The peak value of pressure recorded by sensors located at the top and bottom of the specimen is obviously smaller than that of the central, and the time is also slightly delayed. It was found that the explosion shock wave decays rapidly with the increase of propagation distance in the air.

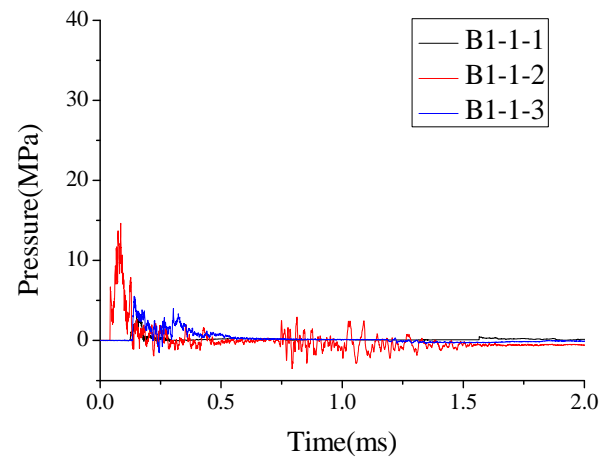

FIGURE III. PRESSURE TIME CURVE OF B1-1

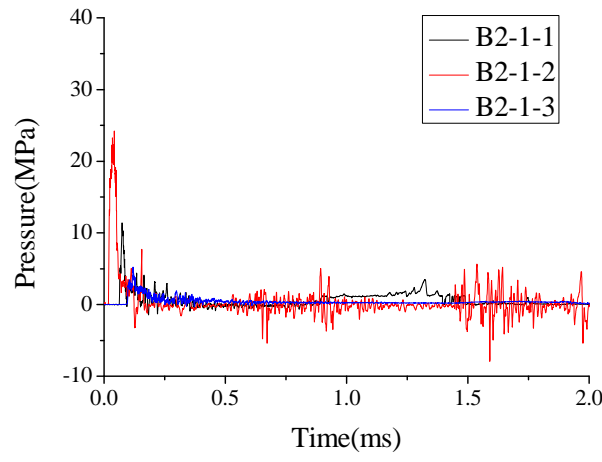

FIGURE IV. PRESSURE TIME CURVE OF B2-1

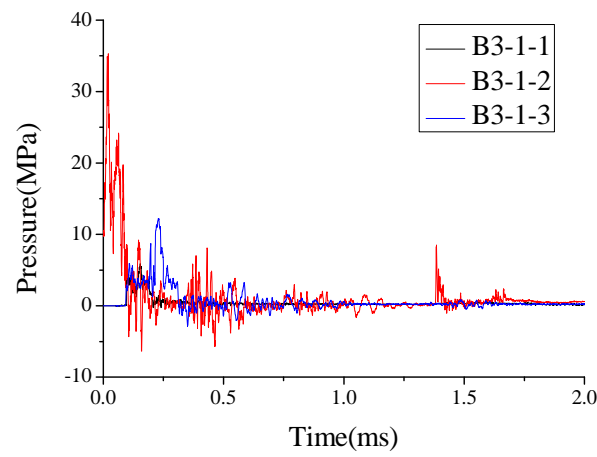

FIGURE V. PRESSURE TIME CURVE OF B3-1 
When the shock wave reaches the sensor about $0.1 \mathrm{~ms}$, a series of reflections were generated on the flange of the specimen, and the pressure time history curve oscillates violently, showing multiple peaks. The increase of the flange width of the component plays a certain role in strengthening the pressure peak of each point, for example: B1-1 specimen central peak pressure is $14.62 \mathrm{MPa}$.The peak value of pressure in the middle part of $\mathrm{B} 2-1$ specimen is $24.30 \mathrm{MPa}$, which is higher than that of $\mathrm{B} 1-19.68 \mathrm{MPa}$; the $\mathrm{B} 3-1$ specimen central peak pressure is $35.27 \mathrm{MPa}$, which is higher than that of $\mathrm{B} 1-1$ 20.65MPa, higher than that of 10.97MPa, as shown in figure 6 .

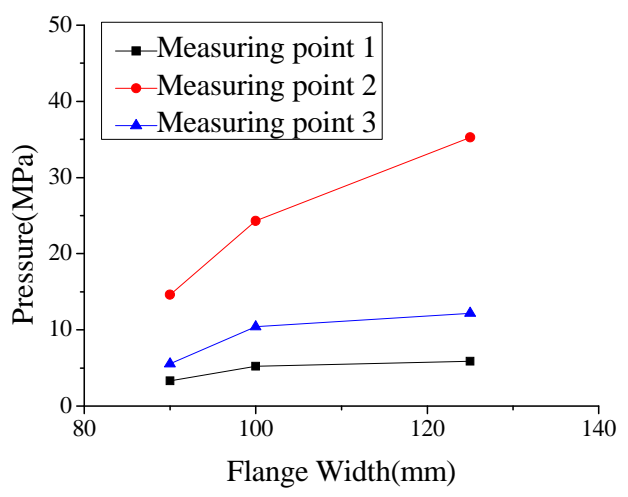

FIGURE VI. COMPARISON OF PEAK PRESSURE UNDER DIFFERENT FLANGE WIDTHS

The width of the flange member changes on the surface of the central component attack effect explosion is large, the influence by the members of the middle to both ends gradually weakened, for example: B1-1, B2-1, B3-1 in the center of specimen measuring point of peak pressure were $35.267 \mathrm{MPa}$, $24.301 \mathrm{MPa}$, $14.620 \mathrm{MPa}$, the difference were $58.54 \%$ and $31.09 \%$.Three cases of specimens at the top point of peak pressure were $5.900 \mathrm{MPa}, 5.231 \mathrm{MPa}$, 3.303MPa, the difference were $44.02 \%, 11.34 \%$.Three cases at the bottom of the sample points of peak pressure were $12.174 \mathrm{MPa}, 10.416 \mathrm{MPa}$, $5.530 \mathrm{MPa}$, the difference were $54.58 \%$ and $14.44 \%$, as shown in Figure 7.

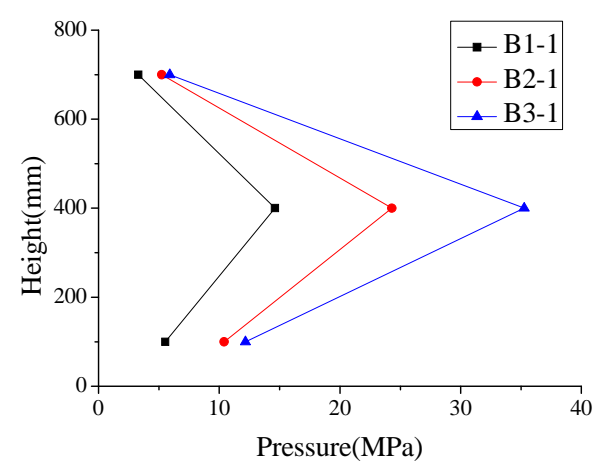

FIGURE VII. COMPARISON OF PEAK PRESSURE

\section{B. Acceleration of Specimens}

As shown in Figure 8. Starting from the detonation time, about $0.1 \mathrm{~ms}$, the acceleration reached the maximum rapidly, then the peak decreased gently, and gradually entered the stationary phase. All the peak curve of 3 tests were $433060 \mathrm{~m} / \mathrm{s} 2,626660 \mathrm{~m} / \mathrm{s} 2,683230 \mathrm{~m} / \mathrm{s} 2$. The acceleration of the specimen subjected to explosion load is affected by flange width. With the flange width increasing, the pressure of specimen increases, and the acceleration of specimen increases. With the flange width increasing to $125 \mathrm{~mm}$, the moment of inertia of the section is larger, the deformation resistance of the specimen increases, and the acceleration ascension is not significant.

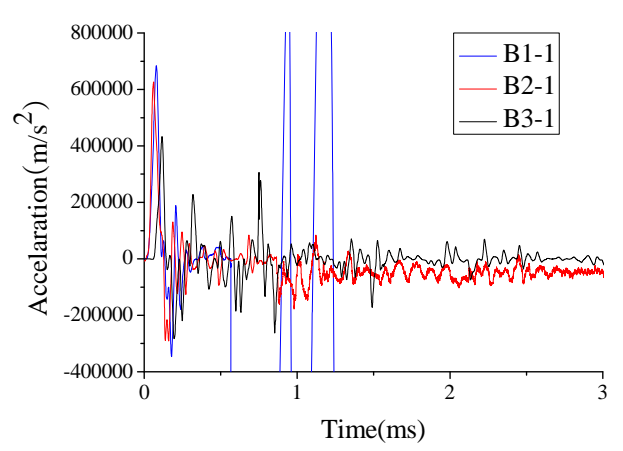

FIGURE VIII. ACCELERATION TIME HISTORY CURES OF SPECIMENS

\section{Strain of Specimens}

The strain of the specimen under blast loading is also affected by flange width. With the flange width increasing, the pressure increases and the specimen strain increases with the flange width increasing.

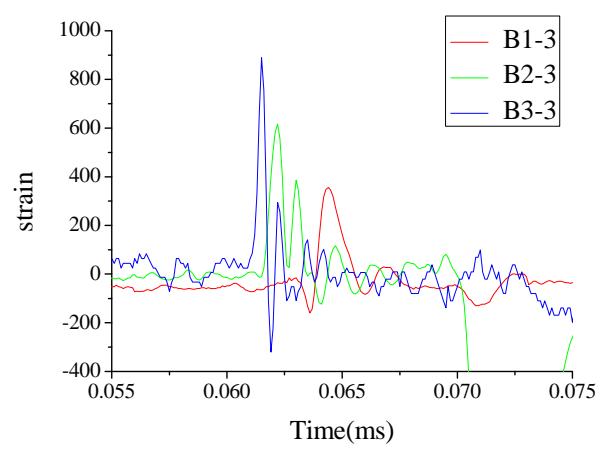

FIGURE IX. COMPARISON OF PEAK PRESSURE UNDER DIFFERENT FLANGE WIDTHS

\section{Deformation}

According to the observation and measurement before and after the test, the deformation of the angle steel member is mainly local yield when the explosive content is small. When the explosive dose is large, the angle steel member is deformed into the combination of local yielding and integral bending, as 
shown in figure 10 . With the increase of flange width, the residual deformation of the specimen increases accordingly.

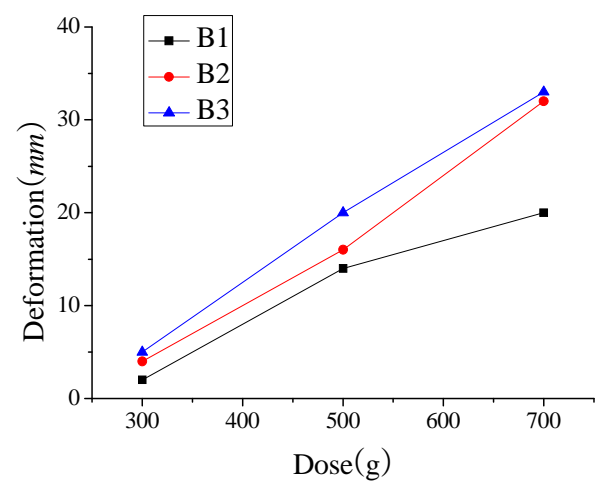

FIGURE X. FCOMPARISON OF PEAK PRESSURE UNDER DIFFERENT FLANGE WIDTHS

\section{CONCLUSIONS}

In this paper, the static explosion tests of 9 test cases were carried out, and the pressure time history curves, acceleration time history curves, strain time history curves and deformation of the corresponding measuring points were obtained. The following conclusions were obtained.

- The equilateral steel member has a special structure, and the explosion shock wave was repeatedly superposed on the detonation surface, and the propagation form was more complex in the diffusion process. The complex structure at the end will aggravate the reflection, superposition and action time of explosion shock wave, which is not conducive to the structural antiknock. The structural design should pay attention to the selection of the dimension of the steel member and the optimization of the end connection.

- With the increased of flange width, the peak value of pressure increased. The acceleration and strain of the specimen were positively related to the shock wave pressure. The value of the pressure increased, the acceleration and strain increased.

- The pressure time curve of each measurement point showed obvious triangle load distribution characteristics. In the near field explosion, the peak value of pressure decreased from both the initiation point and the component to the two ends of the component, and the pressure varied greatly at each height of the member. The pressure distribution along the member height was assumed to be not applicable in this case.

- In the near field explosion test, the deformation of the specimen can be divided into local buckling and overall bending. When used less dosage, the deformation in the middle part of the face was mainly local buckling, and when the dosage, increases gradually, the overall bending phenomenon is gradually obvious.

\section{ACKNOWLEDGMENT}

The authors would like to thank National Natural Science Foundation of China(Program Nos.51508482) for providing funds for this research work.

\section{REFERENCES}

[1] Yu Runqing, Fang Qin, Chen Li. Performance based antiknock design method for building structural components. Engineering mechanics, 2016, (11): 75-83.

[2] Li Shiqiang, Li Xin, Wu Guiying. Dynamic response of graded honeycomb sandwich panels subjected to blast loading .Explosion and shock, 2016, (03): 333-339.

[3] Xia Zhicheng, Wang Xihao, Zhao Yuetang,et al.Study on antiknock performance of steel plate foam aluminum composite panel. Vibration and shock, 2017, (02): 117-122.

[4] Liu Xinrang, Tian Xiaogeng,Lu Tianjian.Study on antiknock performance of foam aluminum sandwich cylinder. Vibration and shock, 2012, (23): 166-173.

[5] Perzyna P.Fundamental problems in viscoplasticity. Adv. Appl. Mech., 1968,9:313-377.

[6] Johnson G R,Cook W H.Fracture characteristics of three metals subjected to various strains, strain rates, temperatures and pressures. Engineering Fracture Mechanics,1985,21:31-48.

[7] Nurick G N,Shave G C.The deformation and tearing of thin squwere plates subjected to impulsive loads-an experimental study.Int.J.Impact Eng.,1996,18:99-116.

[8] Nonaka T.Shear failure of a steel member due to a blast.Int.J.Impact Eng.,2000,24:231-238.

[9] Li Zhong Xian, Liu Zhixia, Hao Hong.Dynamic response analysis of steel structures subjected to blast loading.Building structures, 2006,36 (S): 97-101.

[10] Li Zhong Xian, Liu Zhixia, Ding Yang.Dynamic response and failure modes of steel structures subjected to blast loading.(Proceedings of the Chinese society of architectural architecture, 2008,29 (4): 106-111. 